\title{
Effectiveness of Behavioural Change Communication on Knowledge of Self Care Management of Diabetic Foot Ulcer among Diabetes Patients
}

\author{
Mrs. Vidhya. G*, Dr. G. Bhuvaneshwari, Ms. Priya, Ms. Priyanaka. K. R, Ms. Priyanka. P, Ms. Rohini
}

Department of Community Health Nursing, Saveetha College of Nursing, SIMATS, Chennai, India

DOI: $10.36348 /$ SJNHC.2019.v02i09.007
*Corresponding author: Mrs. Vidhya. G

A descriptive study was conducted to assess the effectiveness of Behavioral Change Communication on knowledge of self care management of diabetic foot ulcer among diabetic clients in Mappedu village. The objectives of the study was to assess the level knowledge on self care management of diabetic Foot ulcer among diabetic client in the pre test, To assess the effectiveness of behavioral change communication on self care management of diabetic Foot ulcer among diabetic client in the post test and To associate the post test level of knowledge with demographic variable Totally 50 samples were selected using convenient sampling technique. The researcher developed a structured interview schedule to assess the demographic variables of the samples.The pre test level of knowledge is assessed using questionarrie and then after completing pre-test the investigator administered vedio assisted teaching on diabetic foot care to the clients. Then the post test were conducted to the samples with the same structured questionnaire. The data were analyzed by using descriptive and inferential statistics. The findings of the study reveals that out of 50 samples in pre test $0(0 \%)$ had adequate knowledge, 17(34\%) had inadequate knowledge 33(66\%) had poor knowledge and in post test 35(70\%) had adequate knowledge, $15(30 \%)$ had inadequate knowledge and $0(0 \%)$ had poor knowledge. The calculated ' $t$ ' value for experimental group was $\mathrm{t}=6.47$ which is found significant at $\mathrm{P}>0.05$ level. So the Behavioral Change Communication on knowledge of self care management of diabetic foot ulcer among diabetic clients is effective.

Keywords: Behavioral Change Communication, diabetic foot ulcer, self care.

Copyright @ 2019: This is an open-access article distributed under the terms of the Creative Commons Attribution license which permits unrestricted use, distribution, and reproduction in any medium for non-commercial use (NonCommercial, or CC-BY-NC) provided the original author and source are credited.

\section{INTRODUCTION}

In 2017 , the international diabetes federation said that the prevalence of diabetes among the adults (20-79 years) in India is 72.9 million. There has been a 1.78 increases in diabetes in the last 10 years, from 40.9million in 2007 to 72.9 million in 2017. Its is likely to increase further by 1.84 - fold (134.3 million) by 2045 [1].

Diabetic foot adds to economic burden due to huge expenditure on treatment, loss of productivity, frequent recurrence of the problem, and high rate of amputation. An estimated 40,000 legs are amputated each year in India, of which $75 \%$ are because of neuropathy and secondary infection and these are potentially preventable. In terms of expenditure, patients without diabetic foot problem spent 9.3\%, whereas patients with foot problem spent $32.3 \%$ of their total income on their treatment. This underscores the importance of prevention of diabetic foot [2].
Diabetic foot ulcer (DFU) is a full-thickness wound penetrating through the dermis (the deep vascular and collagenous inner layer of the skin) located below the ankle in a diabetes patient. If a foot ulcer goes untreated and does not heal, it may become infected [3].

"The development of foot problems is not an inevitable consequence of having diabetes, said Andrew Boulton, chairperson of the American Diabetes Associations Foot Council, Indeed, most foot lesions are preventable. Across the globe, about a quarter of people with diabetes will develop sores or ulcers on their foot. In 2017, the international diabetes federation said that the prevalence of diabetes among the adults (20-79 years) in India is 72.9 million. There has been a 1.78 increases in diabetes in the last 10 years, from 40.9million in 2007 to 72.9 million in 2017 . Its is likely to increase further by 1.84 - fold (134.3 million) by 2045 . 
The foot complications are one of the most serious and costly complications of diabetes but are usually neglected by the diabetics. The International diabetic federation and WHO had chosen the diabetic foot as the theme for the world diabetes day in 2005 with the slogan " put feet first: prevent amputations" [4].

Chamil Vidusha, A study to determine the knowledge and practice of foot care in patients with chronic diabetic ulcers. The objective of the study is to determine the level of knowledge of knowledge and practice of foot care among patients with chronic diabetic foot ulcers. Totally 110 samples were selected from national hospitals of Srilanka (NHSL) for this descriptive cross sectional study. They were given an interview administered, pre test questionnaire. The result of the study is that regarding foot care knowledge, the mean score was $8.37,75.5 \%$ had scored above mean and $52.7 \%$ were aware of all principles of foot care .Regarding foot care practice the participants had scored below mean and they did not practice any foot care principles [5].

Shyam Kishore, Awareness of foot care among patients with diabetes attending a tertiary care hospital .Researcher assessed the awareness of foot care among diabetic patient attending a tertiary care hospital in northern Indian and whether this varied with the level of health care availed, i.e. primary, secondary and tertiary. A score questionnaire was designed based on the foot care practice advised by the American diabetes Association as part of the National diabetes education program [6].

It is estimated that the number of people with diabetes will increase to 439 million by 2030 and to 592 million by $2035[8,9,7]$.

\section{OBJECTIVES OF THE STUDY}

- To assess the level of knowledge on self care management of diabetic Foot ulcer among diabetic client in the pre test

- To assess the effectiveness of behavioral change communication on self care management of diabetic Foot ulcer among diabetic client in the post test.

- To associate the post test level of knowledge with demographic variable

\section{MATERILAS AND METHODS}

Quantative research approach was adopted by the investigators to assess the effectiveness of behavioral change communication on knowledge of self-care management of diabetic foot ulcer among diabetes clients in mappedu village. The samples who met the inclusion criteria were selected by using purposive sampling technique. Inclusion criteria for sample selection are diabetes clients with age group of 45-70 years. Total 50 samples were involved in the research. Data was collected using structured questionnaire to assess the knowledge on diabetic foot ulcers among diabetics clients. The project has been approved by the ethics committee of the institution .Informed consent was obtained from the participants before initiating the study.

\section{RESULTS}

In out of 50 samples $12(24 \%)$ were in the age of $35-45 \mathrm{yrs}, 22(44 \%)$ were in the age group of 45-55yrs and $16(32 \%)$ were in the age of above 55yrs. According to the gender $27(54 \%)$ were males and $23(46 \%)$ were females. According to the Education $36(72 \%)$ were completed their primary education, 4(8\%) were completed their secondary education, $10(20 \%)$ were illiterate and none of their were graduate. According to the duration of diabetes $35(70 \%)$ sample have for less than 10 years and $15(30 \%)$ have for more than 10 years. According to the treatment $33(66 \%)$ were in regular treatment and $17(34 \%)$ were in irregular treatment and According to the diabetes complication, no one in the selected sample had diabetes complication.

To assess the level of knowledge on self care management of diabetic Foot ulcer among diabetic client in the pre test

In out of 50 samples $0(0 \%)$ had Adequate knowledge, 17(34\%) had inadequate knowledge and $33(66 \%)$ had poor knowledge during per test.

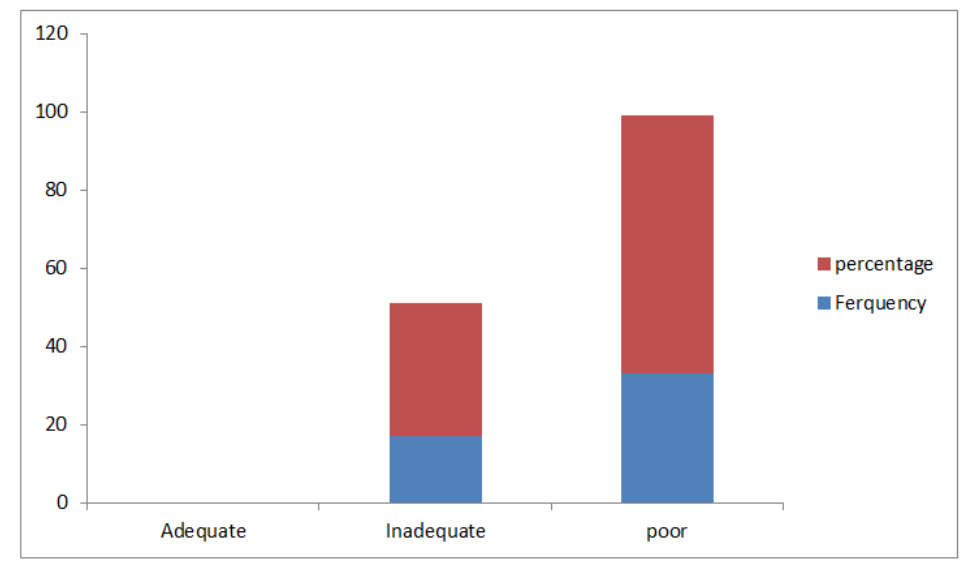


The above graph indicates the frequency and distribution of pre test level of knowledge among diabetes clients out of 50 samples $0(0 \%)$ had Adequate knowledge, 17(34\%) had inadequate knowledge and $33(66 \%)$ had poor knowledge during per test

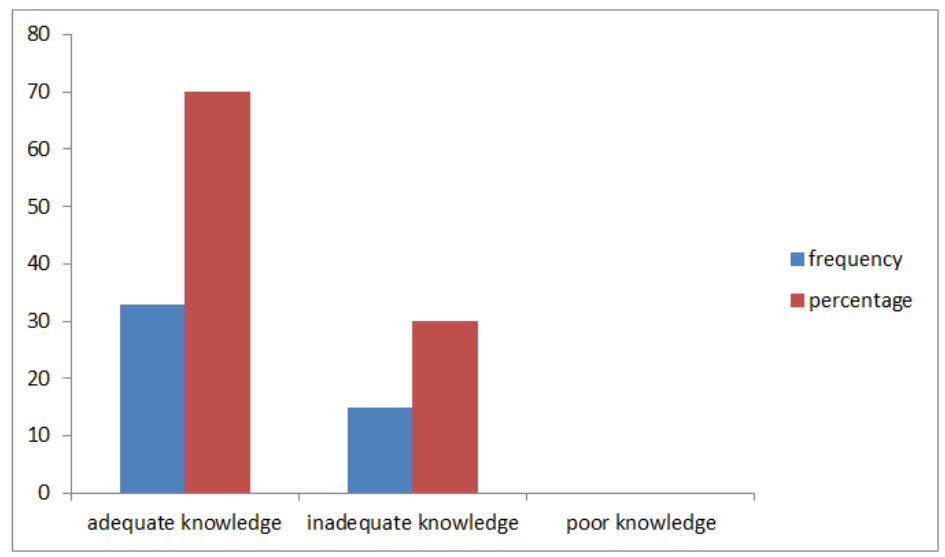

The above graph indicates the frequency and percentage distribution of post test level of knowledge among diabetes clients. That is out of 50 samples $35(70 \%)$ had Adequate knowledge, 15(30\%) had inadequate knowledge and0 $(0 \%)$ had poor knowledge.

Table-1:

\begin{tabular}{|l|l|l|}
\hline Content & Pre test & Post test \\
\hline Mean & 9.72 & 1.8 \\
\hline Standard deviation & 1.260 & 2.28 \\
\hline
\end{tabular}

The above table reveals that the calculated $\mathrm{t}$ value for the experimental group is $t=6.47$ which is found to be significant at $p>0.05$ level and So the behavioral changing communication on knowledge of self care management of diabetic foot ulcer is effective among diabetes clients.

\section{DISCUSSION}

The main focus of the study is to assess the effectiveness of Behavioural Change Communication on knowledge of self care management of diabetic foot ulcer among diabetic clients in Mappedu village. 30 samples were collected by convenient sampling technique.

The pre test was assessed, in that out of 50 samples $0(0 \%)$ had Adequate knowledge, 17(34\%) had inadequate knowledge and $33(66 \%)$ had poor knowledge. The findings of the study conducted by Desalu [10] A study to assess the knowledge and practice of foot care among diabetes clients, supports this study The result of the study shows that $78.9 \%$ have poor knowledge on diabetic foot care, $61.4 \%$ were unaware of inspecting the inside of the shoes and $89.2 \%$ failed to get the appropriate size shoes.

After assessing the knowledge the post testvalue is out of 50 samples $35(70 \%)$ had Adequate knowledge, $15(30 \%)$ had inadequate knowledge and0 $(0 \%)$ had poor knowledge. The findings of the study conducted by the author Gloria Green-Morris [11], An evaluation of the effectiveness of providing foot care education in a rural clinic setting, supports this study. The result of the study show that after educating the diabetic clients about the diabetic foot care, $100 \%$ of participants of participants agreed that checking their foot ulcer are caused by taking care of their feet.77.8\% believes that checking their feet decreased the likelihood of foot ulcer formation and all the participants had the ability to choose shoes that properly feet their feet.

The calculated $\mathrm{t}$ value for the experimental group is $t=6.47$ which is found to be significant at p>0.05 level and So the behavioral changing communication on knowledge of self-care management of diabetic foot ulcer is effective among diabetes clients.

\section{Association of the post test level of knowledge among diabetes clients with demographic variables}

The association between the post level knowledge and demographic variables. Out of 50 sample, Regarding Age the Chi-square value is $\mathrm{X} 2=0.365$ and $\mathrm{df}=2$, Regarding gender $\mathrm{X} 2=0.410$ and $\mathrm{df}=1$, Regarding education $\mathrm{X} 2=2.970$ and $\mathrm{df}=2$, Regarding Duration of diabetes X2 $=0.397$ and $\mathrm{df}=1$, Regarding Diabetes treatment $\mathrm{X} 2=0.238$ and $\mathrm{df}=1$ and Regarding diabetes complication $\mathrm{X} 2=0$ and $\mathrm{df}=0$

\section{CONCLUSION}

The study findings suggest that educating the clients about the diabetic foot care can promote their knowledge and helps in preventing the foot ulcers.

\section{ACKNOWLEDGEMENT}

We would like to extend our gratitude to the authorities of Saveetha college of Nursing.

Conflict of Interset: The authors declare no conflict of interest. 


\section{REFERENCES}

1. The international federation. (2017). Prevalence of diabetes among adults, diabetes research and clinical practice, 138, 271-281.

2. Abbas. (2015). World Diabetes Foundation, Importance of prevention of diabetic foot ulcer.

3. Armstrong, D. G., Cohen, K., Courric, S., Bharara, M., \& Marston, W. (2011). Diabetic foot ulcers and vascular insufficiency: our population has changed, but our methods have not. Journal of diabetes science and technology, 5(6), 1591-1595.

4. International Diabetes federation. (2005). World Diabetes Day: Diabetes and foot care.

5. Chamilvidusha. (2019). A study to determine the knowledge and practice of foot care in patient with chronic diabetic ulcers. International journal of collaborative research on Internal medicine and public health, 115-122.

6. Kishore, S., \& Upadhyay, A. D. (2015). Awareness of foot care among patients with diabetes attending a tertiary care hospital. The National medical journal of India, 28(3), 122-125.
7. Alneami, Y. M., \& Coleman, C. L. (2016). Risk factors for and barriers to control type-2 diabetes among Saudi population. Global journal of health science, 8(9), 10.

8. Guariguata, L., Whiting, D. R., Hambleton, I., Beagley, J., Linnenkamp, U., \& Shaw, J. E. (2014). Global estimates of diabetes prevalence for 2013 and projections for 2035. Diabetes research and clinical practice, 103(2), 137-149.

9. Shaw, J. E., Sicree, R. A., \& Zimmet, P. Z. (2010). Global estimates of the prevalence of diabetes for 2010 and 2030. Diabetes research and clinical practice, $87(1), 4-14$.

10. Desalu, O. O., Wahab, K. W., Fawale, B., Olarenwaju, T. O., Busari, O. A., Adekoya, A. O., \& Afolayan, J. O. (2011). A review of stroke admissions at a tertiary hospital in rural Southwestern Nigeria. Annals of African Medicine, 10(2).

11. Green-Morris, G. (2014). An evaluation of the effectiveness of providing foot care education in a rural clinic setting. 